\title{
Application of Slope Radar (S-SAR) in Emergency Monitoring of the "11.03" Baige Landslide
}

\author{
Xu Wei $\mathbb{i D}^{1,2}$ and Feng Wenkai $\mathbb{D}^{1}$ \\ ${ }^{1}$ Key Laboratory of Geohazard Prevention and Geoenvironment Protection, Chengdu University of Technology, \\ Chengdu 610081, China \\ ${ }^{2}$ China Geological Survey of Chengdu Center, Chengdu 610081, China \\ Correspondence should be addressed to Feng Wenkai; fengwenkai@cdut.cn
}

Received 30 August 2021; Accepted 4 October 2021; Published 27 October 2021

Academic Editor: Gan Feng

Copyright (c) $2021 \mathrm{Xu}$ Wei and Feng Wenkai. This is an open access article distributed under the Creative Commons Attribution License, which permits unrestricted use, distribution, and reproduction in any medium, provided the original work is properly cited.

\begin{abstract}
On October 11 and November 3, 2018, the disaster chain of landslide-barrier lake occurred twice in Baige Village, Xizang Province. After the second sliding of the landslide, the danger of the landslide dam was eliminated by the manual excavation of the drain grooves. During this period, a ground-based interferometric synthetic aperture radar (GB-InSAR) called "S-SAR" was utilized for real-time monitoring and analyzing 48 selected target pixels on the residual deformation bodies of landslides (divided into $\mathrm{K} 1, \mathrm{~K} 2$, and $\mathrm{K} 3$ deformation zones) for 8 days. Through the real-time deformation map of pixels in the monitoring area obtained by S-SAR, the ranges of five strong deformation regions were identified and delineated. Based on the apparent cumulative deformation-time curve of each target pixel, the overall deformation law of K1, K2, and K3 deformation zones could be monitored and analyzed in real time. Based on a curve graph of the deformation rate, acceleration, and time of each target pixel, the $\mathrm{K} 1, \mathrm{~K} 2$, and $\mathrm{K} 3$ deformation zones were within a uniform deformation stage. Taking the target pixel point and the corresponding time in which the deformation rate and deformation acceleration had a large, abrupt jump at the same time as the position and time of the near-slip failure, the 11 positions and moments of the near-slip failure were counted. The results presented here may represent a workable reference for emergency monitoring and early warning of similar sudden geological disasters.
\end{abstract}

\section{Introduction}

In the early morning of October 11, 2018, a large-scale landslide occurred in Baige Village, Jiangda County of the Tibet Autonomous Region, referred to as the "10.11" landslide. The scope of the landslide is shown in Figure 1, the red dotted line. The 10.11 landslide blocked the Jinsha River and formed a barrier dam that was relieved after natural flood discharge. At GMT +8 17:40 on November 3, 2018, the back edge of the landslide area slid again. The scope of the landslide is shown in Figure 1, the yellow solid line; it blocked the river again and formed a larger lake. Excavation of the spillway was completed at GMT +8 16:00 on November 11. At GMT +8 8:00 on November 12 , the water volume of the barrier lake reached $5.2 \times 10^{8} \mathrm{~m}^{3}$. The danger of flood discharge was successfully relieved at GMT +8 10:00 on November 12 as the barrier lake water storage capacity reached $5.2 \times 10^{8} \mathrm{~m}^{3}$. The dangers of flooding were successfully evaded, making this event an example of successful manual intervention in a major barrier lake. The landslide and subsequent flood affected approximately 102,000 citizens in Tibet, Sichuan, and Yunnan provinces. Approximately 86,000 people were relocated, and more than 3,400 homes were collapsed [1].

Failure prediction and early warning of landslides are a popular but challenging endeavour within the geological engineering field. Time-of-failure prediction methods that are based on kinematic parameters can be classified into two groups: empirical methods [2-9] and semiempirical methods [10-16], 2017). Other methods are often associated 


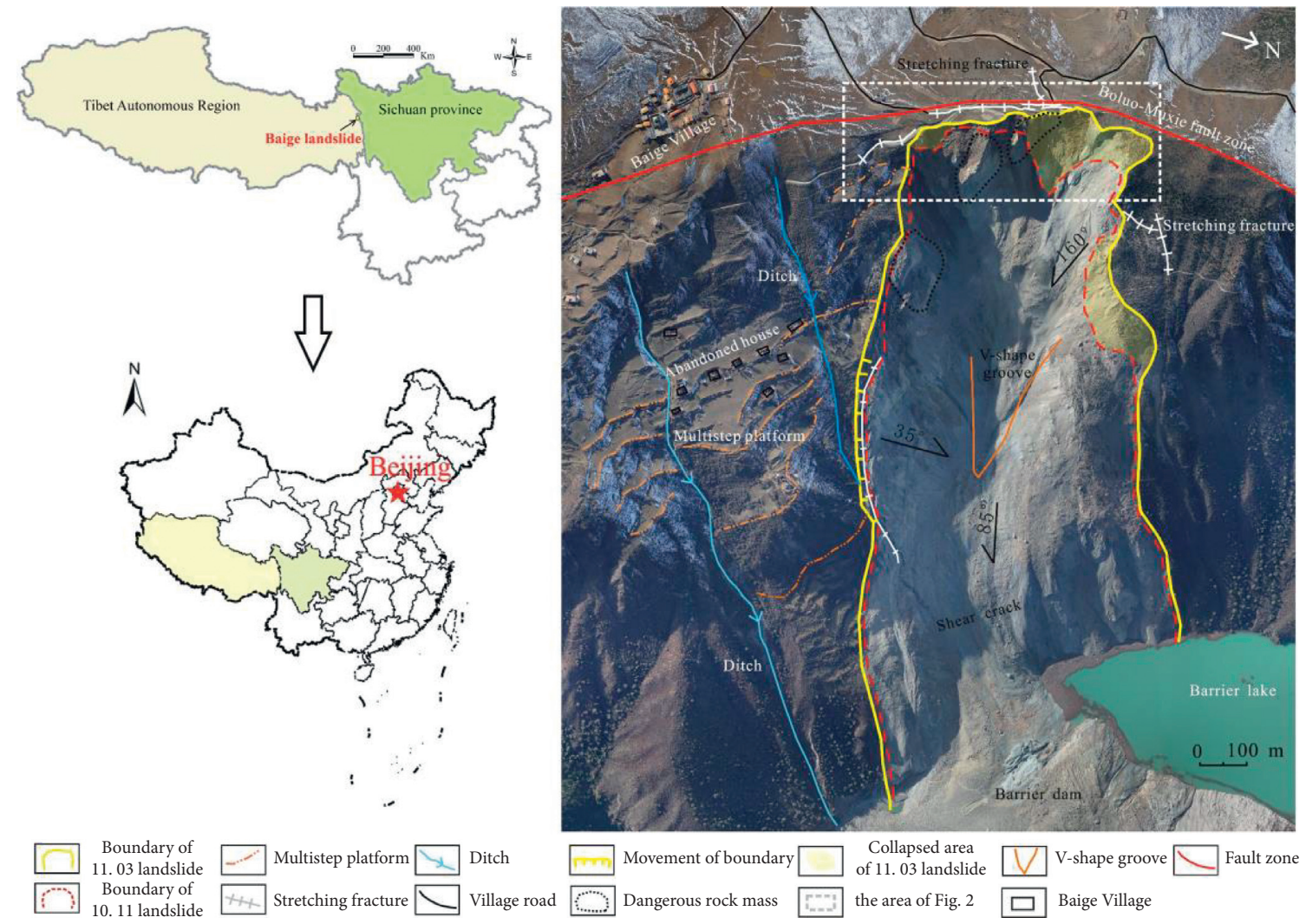

Figure 1: 11.03 Baige landslide plane.

with landslide prediction even though they do not actually provide an estimation of the time of failure: numerical methods [17-25] and methods for the definition of thresholds [26-32].

Future trends in landslide prediction will also be fostered by technological advancements in monitoring techniques. The most striking example is related to recent developments in interferometric satellites. A continuous check of satellite data would have permitted scientists to properly forecast deadly events such as the Xinmo landslide (Maoxian, China) in 2017 [33], which caused $>100$ casualties, and a landslide in an undisclosed copper open-pit mine that killed several workers [34]. Even terrestrial instruments are changing which were only recently considered as consolidated assumptions. For example, the capability of modern GBInSAR apparatuses to monitor areas (not only single points) in a few tens of seconds enables us to further push the limits of what was considered (near) real-time monitoring $[9,35,36]$. GB-InSAR also has the advantage of performing measurements over a broad coverage area (instead of on single discrete points) [37].

Based on field investigation and the interpretation of UAV aerial images, the basic characteristics of the 11.03 landslide and the deformation pattern of the landslide mass were analyzed in this study. The Beidou displacement monitor and crack displacement metre data of the 11.03 landslide indicate that the main rock body experienced three separate accelerated stages before beginning to slide. During the excavation and construction of discharge grooves, we applied an S-SAR for deformation monitoring and early warning forecasting, delimited the $\mathrm{K} 1, \mathrm{~K} 2$, and $\mathrm{K} 3$ areas, and identified 48 meaningful points on the cumulative deformation map. The revisiting time was 15 minutes with a total monitoring time of eight days. The strong deformation zone was identified accordingly. Near real-time monitoring of K1, $\mathrm{K} 2$, and $\mathrm{K} 3$ was performed, and the deformation evolution stages of the landslide were defined. We also conducted hazard area identification and judgement, sliding warning threshold value calculation, and slip damage identification and prediction before summarizing the radar monitoring results of the survey slope. The construction of a Weir Plug dam spillway and the removal of dangerous barrier lakes are recommended according to the results.

\section{11.03 Landslide Characteristics and Deformation Pattern}

2.1. Basic Characteristics of Landslides. The 11.03 landslide was located in Jiangda Village, Tibet Autonomous Region. The geographical coordinates are longitude $98^{\circ} 41^{\prime} 52.15^{\prime \prime}$ and north latitude $31^{\circ} 4^{\prime} 54.91^{\prime \prime}$. The landslide occurred at a linear distance of $144 \mathrm{~km}$ from the nearest major city, $65 \mathrm{~km}$ from Jiangda village and $17 \mathrm{~km}$ away from Baiyu town. The landslide is geographically characterized by the Hengduan Mountain Range and Jinsha River Valley of eastern Tibet, which is a typical tectonic erosion landform. The landslide area encompassed the Jinshajiang tectonic belt between Changdu-Simao and Dege-Zhongdian landmasses. 
The peak acceleration of ground motion in the area where the landslide was located was 0.20 g. On August 12, 2013, the neighbouring Zuogong and Mangkang counties at the junction of the north latitude $30.0^{\circ}$ and $98.0^{\circ}$ east longitude experienced a 6.1 magnitude earthquake. There was no significant seismic activity in the area just prior to the landslide.

The elevation of the 11.03 landslide is $2880-3720 \mathrm{~m}$. The height difference between the front and rear margin is approximately $840 \mathrm{~m}$. The sliding direction of the main sliding body of the " 10.11 " landslide was $85^{\circ}$. The back edge and the left/right sides of the landslide are bounded by exposed fresh bedrock. The shear outlet is located at the foot of the slope approximately $70 \mathrm{~m}$ above the river surface. The slope profile of the landslide is in the form of a fold line with an average slope length of approximately $1420 \mathrm{~m}$. Gullies developed on the right side of the landslide filled with seasonal running water. The plane shape is an irregular rectangle wider from the middle to the back and towards the front. The average slope width is approximately $570 \mathrm{~m}$, and the landslide area is approximately $60 \times 10^{4} \mathrm{~m}^{2}$. The lithology of the outcrop layer in the landslide area is the Proterozoic Xiongsong group $\left(P_{t} x n^{a}\right)$. Gneiss assemblages lie in the west Wari ophitic belt $\left(\psi_{w_{4}}\right)$, as shown in Figure 1 .

After the landslide occurred, there were several tensile fractures on the platform at the back edge, the longest of which was approximately $290 \mathrm{~m}$, extending along the NNW direction, approximately parallel to the BorotMuxie fault. The upper part of the left side boundary (the upstream side) of the landslide had a tensile crack, approximately $150 \mathrm{~m}$ in length, which was nearly parallel to the left side boundary. There was a tension crack in the middle and lower parts of the right side boundary (the downstream side) of the landslide, which was approximately $550 \mathrm{~m}$ in length and nearly parallel to the right side boundary. The downward fault of the crack was obvious. A bank slope landslide was on the right side of the south border, and there were seven displaced platforms from top to toe. The displacement direction was approximately $45^{\circ}$, roughly along with the airport for the Baige landslide slope foot. A total of 16 homes and 110 people were relocated in 2013.

2.2. Characteristics of Metamorphosis. Combined with topography and surface deformation signs, the slide body of the 11.03 landslide can be divided into the $\mathrm{K} 1, \mathrm{~K} 2$, and $\mathrm{K} 3$ deformation zones.

The K1 deformation region was the posterior residual after two landslides. The main sliding body of the 11.03 landslide is shown in Figure 1 with a volume of approximately $356 \times 10^{4} \mathrm{~m}^{3}$ [38]. The free face direction has a slope of $85^{\circ}$, a trailing surface with two landslides that further expanded the international airport. The free face was a nearly upright and inverted triangle, and there were still two pieces of dangerous rock in the middle. The opening condition was good, and there was a possibility of collapse. The volume was estimated to be approximately $55 \times 10^{4} \mathrm{~m}^{3}$, and small stones often fell during monitoring, as shown in Figure 2.
The K2 deformation area was the slope body on the right side of the landslide. In the case of the 11.03 landslide, there was a small-scale collapse on the downstream side of the slope top, with a volume of approximately $12 \times 10^{4} \mathrm{~m}^{3}$ [38]. The bounds of $\mathrm{K} 2$ were rectangular in shape, the surface direction was approximately $35^{\circ}$, with trailing edge boundaries visible through cracks from high to low, and the slope had the shape of a $\mathrm{V}$ groove under the direction of the fault. The back wall was staggered with an elevation difference of approximately $2-3 \mathrm{~m}$. There was the possibility of collapse, and the falling direction was along the free surface, with a local estimated volume of approximately $240 \times 10^{4} \mathrm{~m}^{3}$, often with surface soil collapse during monitoring, as shown in Figure 2.

The K3 deformation area was the left slope of the landslide, and the shallow surface rock and soil body also underwent small-scale collapse during the 11.03 landslide. The K3 area has a narrow width and can be divided into two parts. K3-1 is the upstream side of the upper slope, and the deformation body wall surface is smooth. The airport had a plane direction of approximately $160^{\circ}$, and the volume of the area was estimated to be approximately $120 \times 10^{4} \mathrm{~m}^{3}$. During monitoring, topsoil and rock mass collapsing often occurred along the slide face, as shown in Figure 2. K3-2 was the lower part of the upstream side of the landslide, with an "inverted bell shape," and the overall stability was good. There was the possibility of shallow collapse, and an instability collapse causes a rise in the water level of barrier lake, and the estimated volume was approximately $62 \times 10^{4} \mathrm{~m}^{3}$.

\section{Principle of S-SAR Deformation Monitoring}

The slope synthetic aperture radar (S-SAR) is a GB-InSAR monitoring and early warning system [39]. S-SAR allows for the long-range, continuous monitoring of fixed points. A preset slope deformation amount and deformation rate threshold can be optimized to facilitate early warning of disasters in regions where landslides are possible.

As shown in Figure 3(a), a high-precision linear rail in the S-SAR carries radar interferometer and transceiver bifurcations to continuously transmit high-frequency electromagnetic signals in a fixed-polarization manner; the signals are reflected by the slope target area so that echo signals are continuously received. SAR complex images of the monitoring area are obtained after pulse compression, beam sharpening, and imaging processing. At a fixed time interval (revisiting time) as the slope is monitored, two SAR complex images are created, as shown in Figure 3(b). If a target point on the slope or the target area is deformed slightly in the two image scans, the displacement of the space target moved from point $A$ to point $B$, point $A^{\prime}$ to point $B^{\prime}$, which means when two radar images present interference, the corresponding pixel phase difference can be used to determine the displacement (deformation) of the two point targets. The interference unit within the corresponding phase values reflects the radar antenna and target as the slope of the line-of-sight (LOS) deformation. The deformation is the actual displacement component along the LOS direction, which is referred to here as the apparent deformation. The 


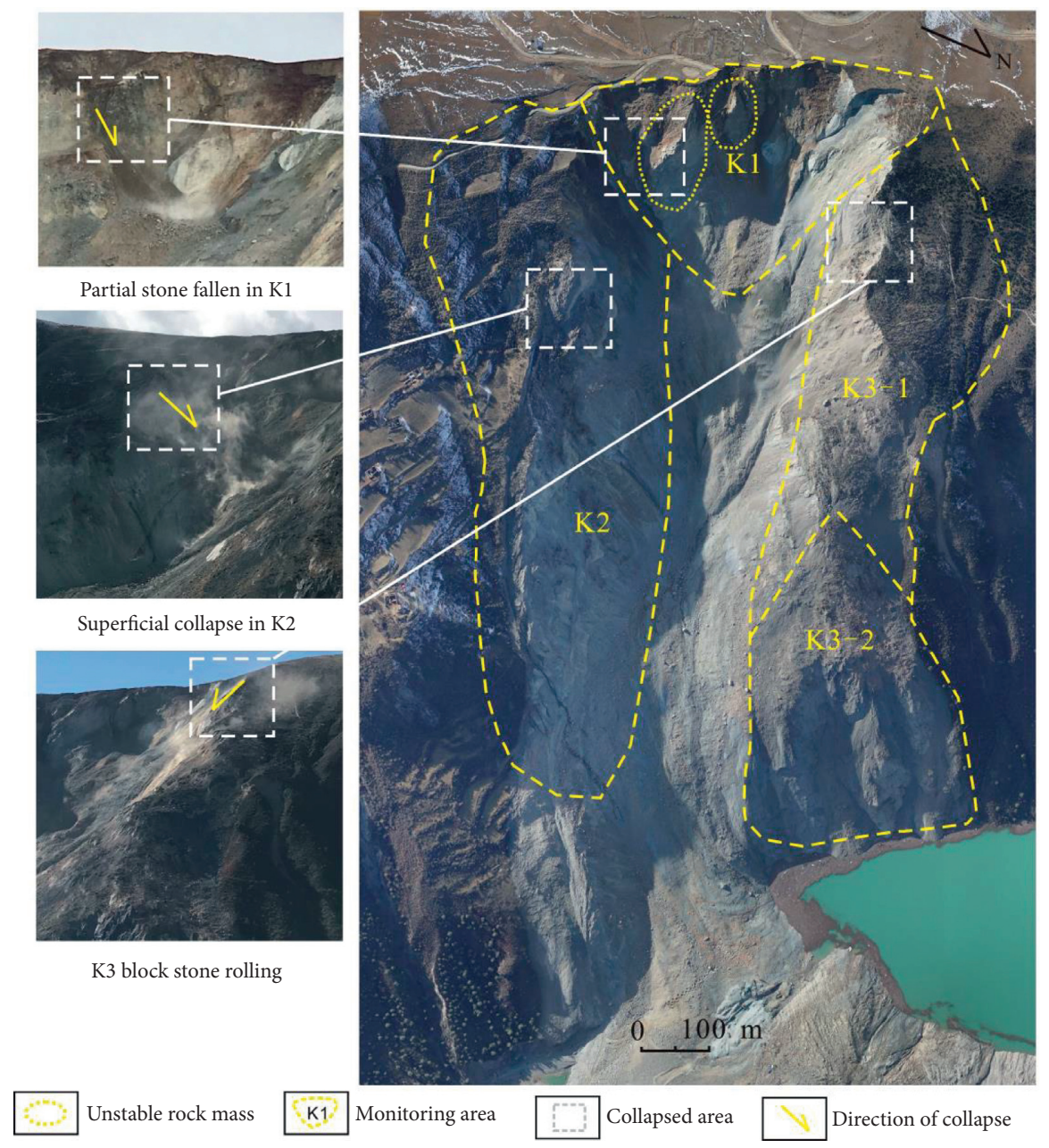

Figure 2: K1, K2, and K3 deformation zones.

symbol reflects that the deformation target moves relatively far from or near to the radar. Many researchers have verified the high accuracy of S-SAR [37].

\section{Application of S-SAR in Emergency Management}

4.1. Identification and Delineation of Strong Deformation Zones. The primary purpose of the S-SAR is to identify and determine the deformation conditions of a given slope surface. S-SAR results may divide the monitoring area into several continuously distributed pixels, where each pixel is the minimum unit of an S-SAR monitoring result. Different colors represent the variation of cumulative apparent deformation displacement of different pixels. The real-time deformation map of the monitoring area can be displayed on the computer of the slope radar, which can not only quickly identify the strong deformation area of the monitoring area but also click on any pixel to view the cumulative apparent deformation-time curve of the point. All the monitoring data of the point can be downloaded for later data analysis.

The monitoring period in this study was every 15 minutes beginning at GMT+8 14:20 on November 8, 2018, and ending at GMT+8 4:04 on November 16, 2018. The eight-day period was divided into two stages: the emergency construction stage (GMT+8 14:20 on November 8 to GMT+8 00:00 on December 12) and the postrelease stage (GMT+8 00:00 on December 12 to GMT+8 4:04 on November 16). To grasp the real-time deformation of K1, K2, and $\mathrm{K} 3$ areas, multiple target pixels were selected from several pixel points to monitor their deformation in real time. The principles of selection were as follows: (1) at the beginning of monitoring, because the distribution of the strong deformation zone in the monitoring area was not clear, the uniform selection method was adopted in K1, K2, and $\mathrm{K} 3$ deformation areas; (2) with the continuation of monitoring, the strong deformation area in the real-time deformation map of the monitoring was going to be gradually identified and updated, and the number of target pixels would be increased in the strong deformation area to strengthen the monitoring. By the end of the monitoring, a total of 48 target pixels were selected, including 11 target pixels (J1-J6, J39-J42, and J48) in the K1 deformation area, 8 target pixels (J7-J14) in the K2 deformation area, and 29 target pixels (J15-J38 and J43-J47) in the K3 deformation area, as shown in Figures 4 and 5.

The real-time pixel cloud deformation map shown in Figure 5(b) intuitively reflects the strength variations in the 


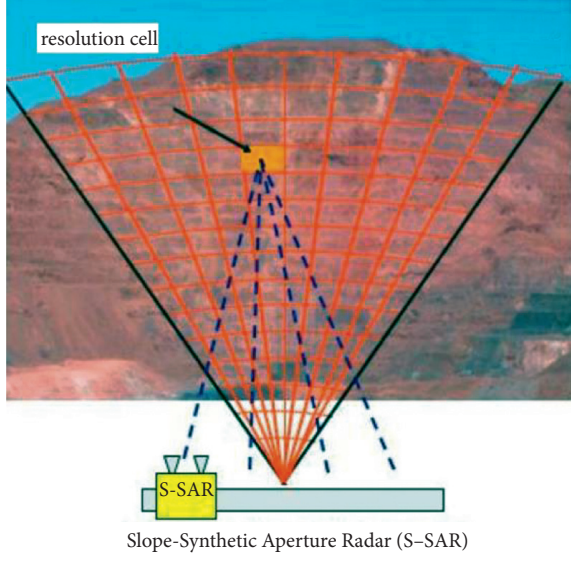

(a)

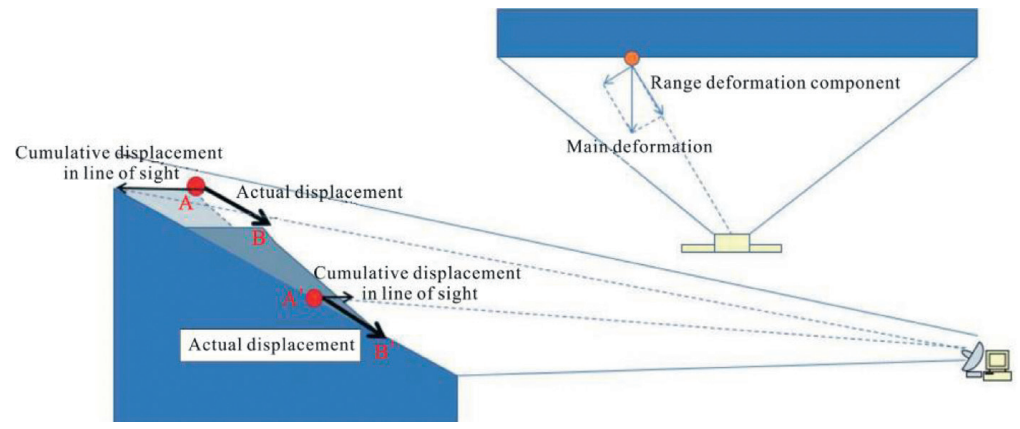

(b)

FIgURE 3: Schematic diagram of slope radar deformation monitoring. (a) The yellow highlighted area marks the S-SAR signal space in contrast to the real slope area; the resolution unit is a small fan-shaped surface element composed of a range-oriented resolution and spatial azimuth resolution. (b) Distance profile and azimuth diagram of actual target displacement on the monitored slope and shape variable monitored by S-SAR.

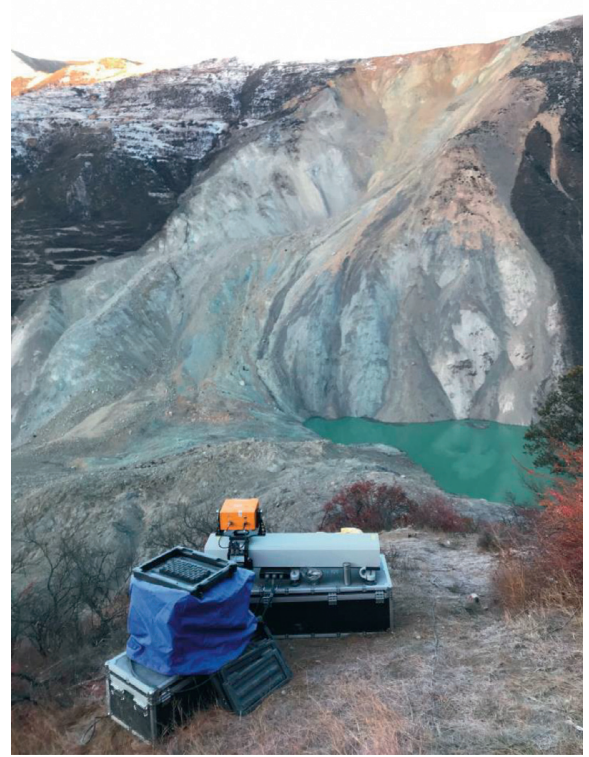

Figure 4: Field monitoring photos of the slope radar.

accumulated apparent deformation in the three deformation zones. Colors range from green, yellow, red, and light blue, corresponding to "weak" to "strong" deformation, respectively. The deployment map of the target pixels delimits the range of strong deformation zones, as shown in Figure 5(a).
The deformation zones are mainly distributed in four distinct regions, and the characteristics of each deformation zone are shown in Table 1.

4.2. Near Real-Time Monitoring of Overall K1, K2, and K3 Area Deformation Rules. The S-SAR generates a cumulative apparent deformation-time curve of target pixels in near real time. In the emergency excavation stage, it is crucial that all relevant personnel fully understand the deformation pattern of the hazardous zone. Figures 6-8 show the cumulative apparent deformation-time curve of each target pixel (where slight cumulative deformation and no displacements occurred). As shown in Figure 6, in the emergency excavation stage, the accumulated apparent deformation at the lower part of the multiple free faces on the downstream side of the deformation body (J5) is the largest among the target pixels. The accumulated apparent deformation reached $49.7 \mathrm{~mm}$ at its peak. In the barrier lake release stage, the accumulated apparent deformation of the middle and upper parts of the free face on the downstream side of the deformation body (J39, J40, and J41) and the central part of the deformation body (J6) is the largest; the accumulated apparent deformation of $\mathrm{J} 40$ reached a maximum of $75.8 \mathrm{~mm}$. The fitting formula of J40 and J5 is shown below. The fitting formula can provide a reference and basis for judging the deformation trend in the later stage.

$$
\begin{gathered}
J 40: y=-0.08 t^{5}+1.835 \times 10^{4} t^{4}-1.6 \times 10^{9} t^{3}+6.9 \times 10^{13} t^{2}-1.5 \times 10^{18} t+1.3 \times 10^{22} ; \quad R^{2}=0.97 \\
J 5: y=-0.03 t^{5}+7.03 \times 10^{3} t^{4}-6.1 \times 10^{8} t^{3}+2.65 \times 10^{13} t^{2}-5.75 \times 10^{17} t+5 \times 10^{21} ; \quad R^{2}=0.9799
\end{gathered}
$$

The whole curve of the $\mathrm{K} 1$ deformation area presents undulating oscillation characteristics. In the two time periods from 19:10 on $13^{\text {th }}$ to $3: 27$ on $14^{\text {th }}$ and 19:03 on $14^{\text {th }}$ to
2:05 on $15^{\text {th }}$, the cumulative apparent deformation-time curve steeply increases, and short-duration accelerated deformation appears to occur. The average deformation rate of 


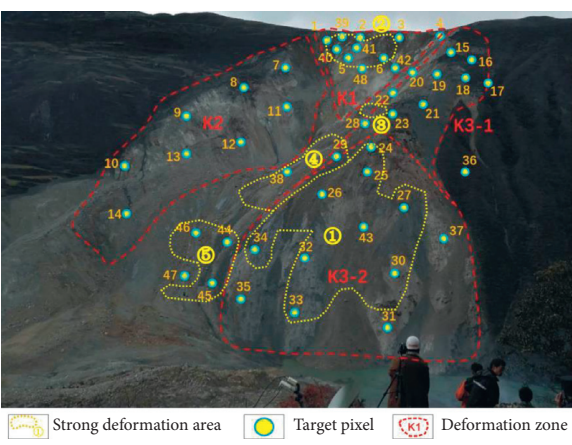

(a)

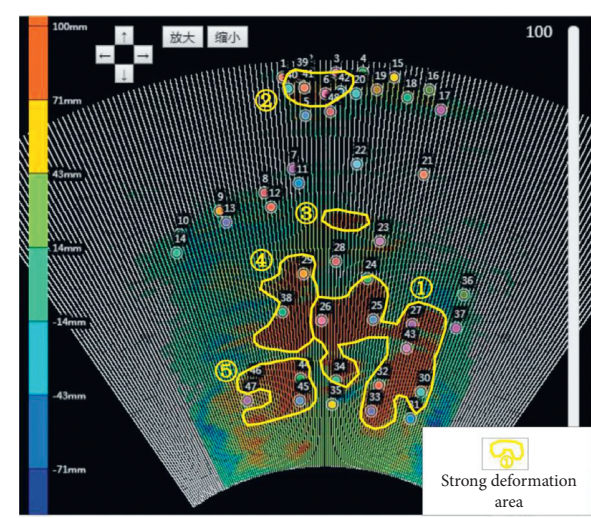

(b)

Figure 5: (a) Deployment of S-SAR target pixels. (b) Real-time cumulative deformation map.

TABle 1: Strong deformation area statistical characteristics.

\begin{tabular}{lccc}
\hline No. & Location & Estimated area $\left(\mathrm{m}^{2}\right)$ & Cause of strong deformation \\
\hline (1) & K3-2 & 61000 & Shallow residual slope soil and cataclastic rock mass collapse \\
(2) & K1 & 14000 & $\begin{array}{c}\text { Slope face loose stone fall } \\
\text { (3), (4) }\end{array}$ \\
$\begin{array}{c}\text { V-shaped groove } \\
\text { area }\end{array}$ & Cut the exit & 13200 & $\begin{array}{c}\text { Top of V-shaped groove and falling blocks on both sides scrape the surface } \\
\text { Surface landslide deposits, shallow residual slope soil, and cataclastic rock mass } \\
\text { collapse }\end{array}$ \\
\hline
\end{tabular}

each target pixel reached $1.88 \mathrm{~mm} / \mathrm{h}$ and $1.39 \mathrm{~mm} / \mathrm{h}$, respectively.

As shown in Figure 7, deformation was largest in the central part of K2 (J13) at a maximum value of $39.8 \mathrm{~mm}$ at GMT+8 16:09 on November 12. The deformation characteristics of the $\mathrm{K} 2$ area were characterized by oscillation and time correlation. The oscillation is more obvious and occurs over a larger range in the $\mathrm{K} 2$ region than in the $\mathrm{K} 1$ region. The J13 and J10 curves are the most representative of these alternating peaks and troughs (with five of each in total). The appearance of wave peaks and troughs is consistent with thawing-freezing, day-to-night cycles. Peaks and troughs occur between 4 and 6p.m. and between 5 and 9a.m. The highest morning temperature in the landslide area was $7^{\circ} \mathrm{C}$, and the low temperature was $-10^{\circ} \mathrm{C}$; the largest temperature difference was $17^{\circ} \mathrm{C}$, occurring from 6p.m. to 5a.m. the following morning. As the temperature fell to below $0^{\circ} \mathrm{C}$, water in the lower part of the slope surface soil and rock joints gradually froze and expanded. Between 9a.m. and 4p.m., the temperature gradually increased, and the resulting thawing increased the water content of the rock and soil mass, decreased the shear strength, and caused the collapse of the surface slope body at the target pixel.

As shown in Figure 8, in the middle part of the slope foot of the landslide where J44 is located, continuous collapse of the shallow surface rock and soil mass produced the maximum apparent deformation in the observation area. This target pixel also showed the largest accumulated apparent deformation among all target pixels. The curves of the K3 deformation zone continually increased over the observation period and fluctuated within a relatively small range. The fitting formula of J44 and J43 is shown below. The fitting formula can provide a reference and basis for judging the deformation trend in the later stage.

$$
\begin{aligned}
& J 44: y=-0.58 t^{3}+7.6 \times 10^{4} t^{2}-3.3 \times 10^{9} t+4.783 \times 10^{13} ; \quad R^{2}=0.99 \\
& J 43: y=0.19 t^{3}-2.52 \times 10^{4} t^{2}+1.1 \times 10^{9} t-1.59 \times 10^{13} ; \quad R^{2}=0.99
\end{aligned}
$$

4.3. Determining the Deformation Zone. The correct judgement of slope deformation evolution stages is the basis for accurate early landslide warning [40-42]. There are three basic deformation stages that occur as the landslide evolves: initial deformation, constant deformation, and accelerated deformation. The deformation rate and deformation acceleration of each target pixel can be calculated according to the accumulated apparent deformation data of each target pixel as obtained by the S-SAR. The stage that the deformation area has reached can then be determined by analyzing the deformation rate-time and deformation acceleration-time curve.

Take the J40 target pixel, which has the largest accumulated apparent deformation in the $\mathrm{K} 1$ area, as an example. 


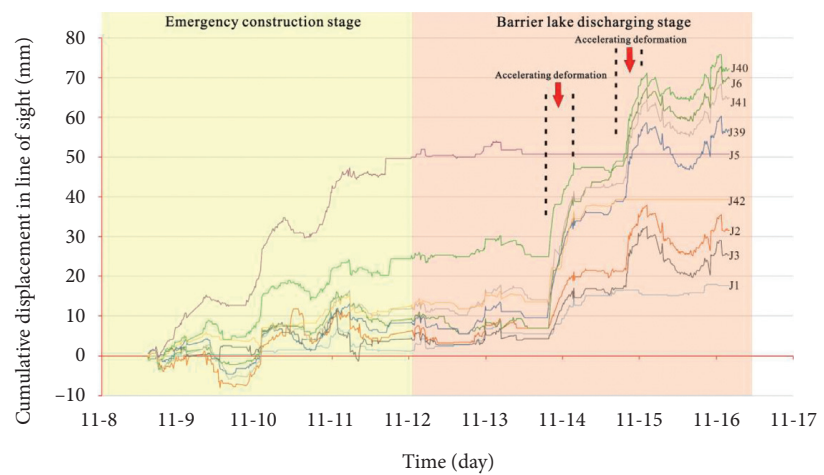

FIgURE 6: Cumulative apparent deformation-time curve of each target pixel in the K1 area. Note: a positive value represents the deformation target moving away from the radar, slipping or falling. A negative value represents the deformation target moving relatively close to the radar, i.e., being covered by rock-soil accumulation.

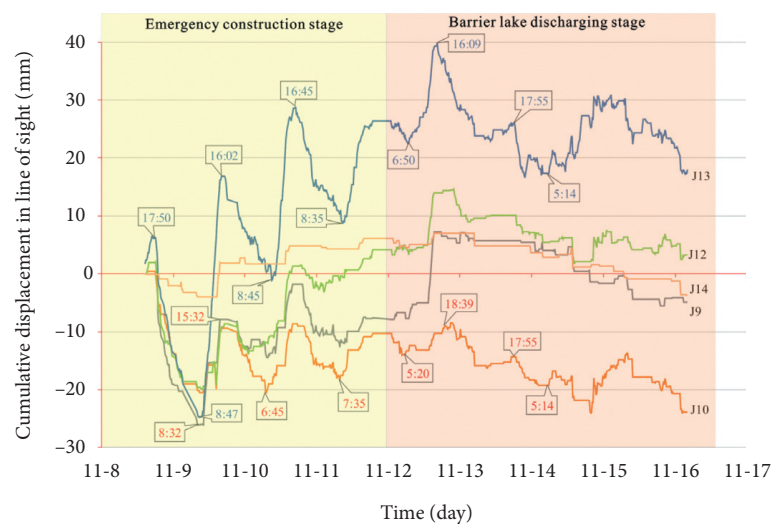

Figure 7: Cumulative apparent deformation-time history (day) curve of each target pixel in the K2 area.

Figures 9 and 10 show the relation curves of the J40 deformation rate and deformation acceleration/time, respectively. As shown in Figure 10, the deformation rate of the slope in the $\mathrm{K} 1$ deformation zone is basically $0 \mathrm{~mm}$ (15 min) across the whole monitoring period. Oscillations occur within $0.4 \mathrm{~mm}(15 \mathrm{~min})^{-1}$, representative of constant deformation characteristics. The curve shown in Figure 11 has a similar constant deformation rate-time curve with a deformation acceleration of approximately $0 \mathrm{~mm}(15 \mathrm{~min})^{-2}$. Oscillations have a mean value of approximately 0 at $0.03 \mathrm{~mm}(15 \mathrm{~min})^{-2}$. Within this range, again, constant deformation can be observed.

The J13 and J44 target pixels serve as additional examples as they have the largest cumulative deformation in the K2 and K3 areas. Their relation curves of deformation rate and deformation acceleration/time are shown in Figures 11-14. The four curves show similar characteristics to those in the K1 region. The deformation rate and deformation acceleration oscillate up at approximately 0 ; the amplitude of the deformation rate oscillations is $0.3(15 \mathrm{~min})^{-1}$. Within the given range, the amplitude of oscillation of the deformation acceleration is $0.03 \mathrm{~mm}(15 \mathrm{~min})^{-2}$. Within this range, the $\mathrm{K} 2$ and $\mathrm{K} 3 \mathrm{de}-$ formation zones are in a stage of constant deformation.

Before the landslide enters the critical slip stage, the acceleration shows a sharp oscillation. The amplitude of oscillation was limited to a certain range in the 11.03 Baige landslide. The S-SAR monitoring deformation acceleration critical slip warning value can be set according to $0.03 \mathrm{~mm}$ $(15 \mathrm{~min})^{-2}$. This value is not fully accurate or unique but can be used to correctly identify any abnormal jumps in acceleration. The value can also be further adjusted as a warning indicator of an impending slide over a longer monitoring period.

4.4. Identification and Prediction of Local Slip Damage in the Deformation Zone. As shown in Figure 15, the velocitytime curve is based on the monitored deformation rate, deformation acceleration-time curve, and real-time dynamic deformation of the area. The acceleration deformation rate of each monitoring station may jump sharply at the same time corresponding to the moment and location of sliding damage; these data can be coupled with the visual surveillance and multiphase UAV aerial image contrast results. The location of target pixels under an impending slide must be reported immediately to headquarters to facilitate early warning. As shown in Figures 9-14, again with target pixels J40, J13, and J44 in the $\mathrm{K} 1, \mathrm{~K} 2$, and $\mathrm{K} 3$ areas, respectively, as examples with the largest accumulated apparent deformation, 11 possible moments of imminent slip failure were identified (Table 2). 


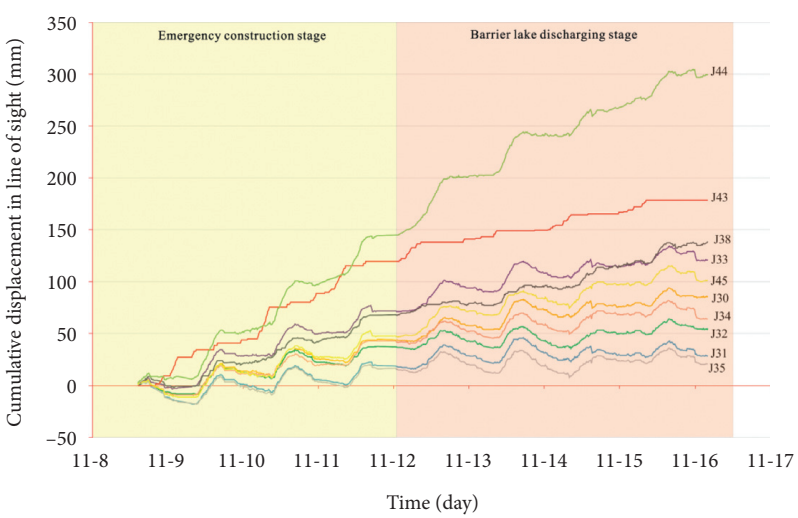

FIgURE 8: Cumulative apparent deformation-time history (day) curve of each target pixel in the K3 area.

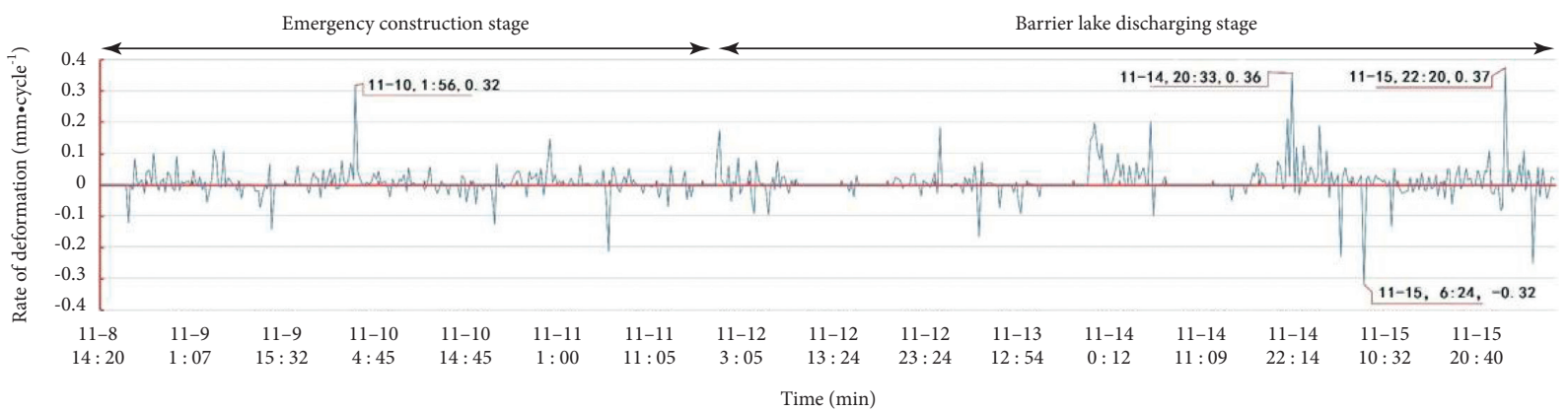

Figure 9: Deformation rate-time curve of K1 region J40. Note: as the above, the positive value indicates that the location of the pixel collapses or falls, and the apparent deformation increases; the negative value indicates that the location of the pixel is covered by the accumulation of rock and soil, and the apparent deformation decreases.

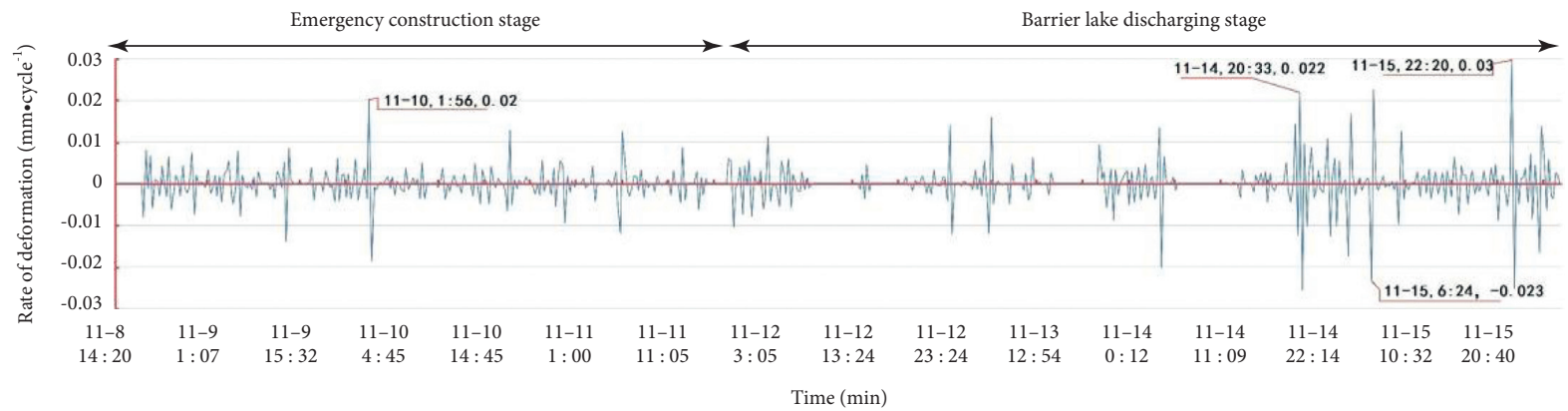

FIGURE 10: Deformation acceleration-time curve of K1 region J40. Note: a positive value represents an accelerated movement of the target. A negative value represents a decelerated movement of the target.

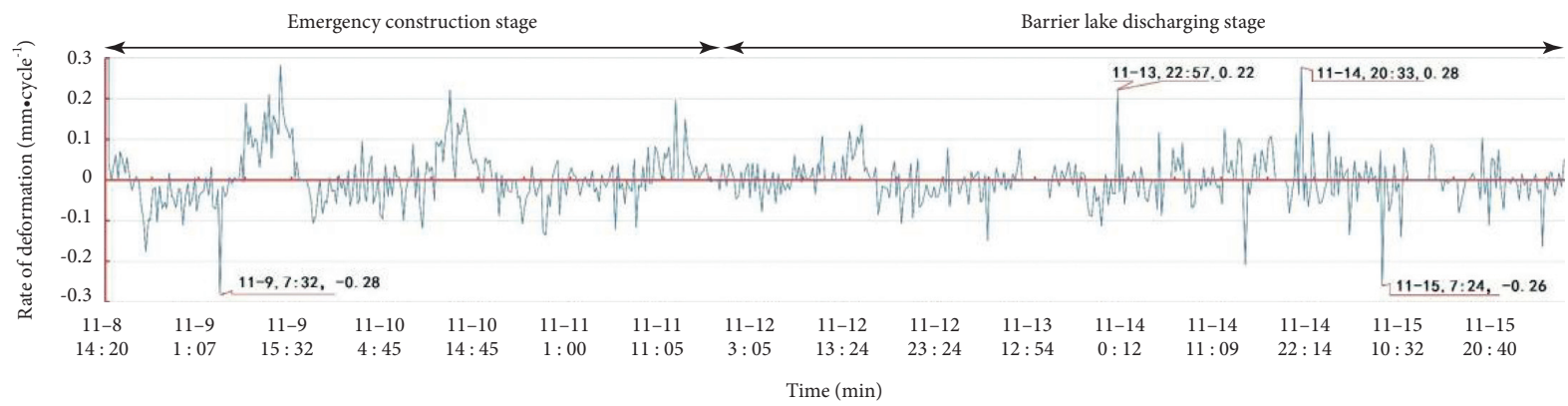

FIGURE 11: K2 J13 deformation rate-time curve. Rate of deformation: $\left(\mathrm{mm} \bullet \mathrm{cycle}^{-1}\right)$. 


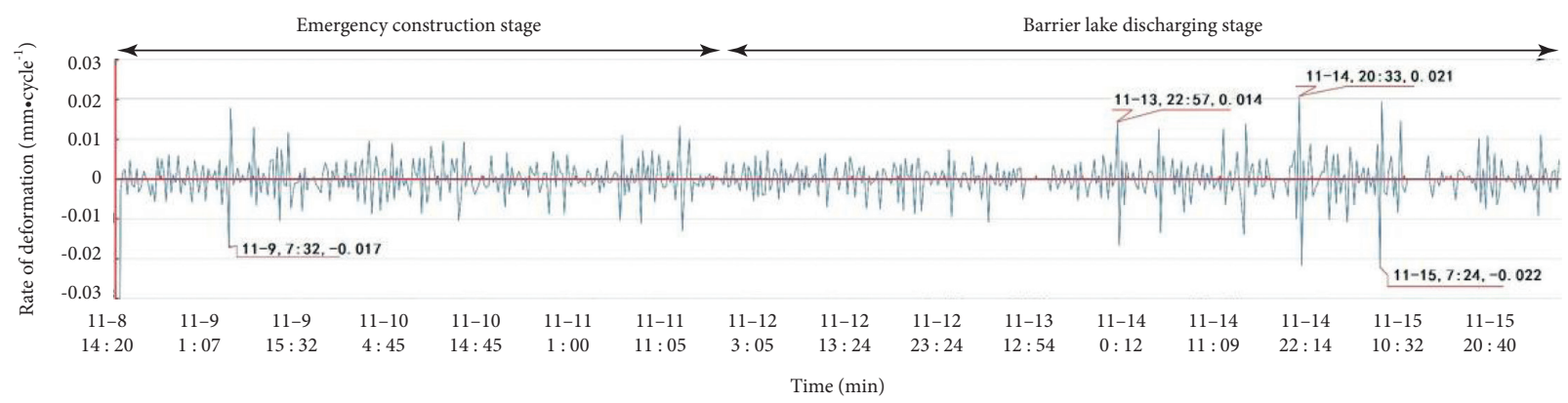

FIgURE 12: K2 J13 deformation acceleration-time curve.

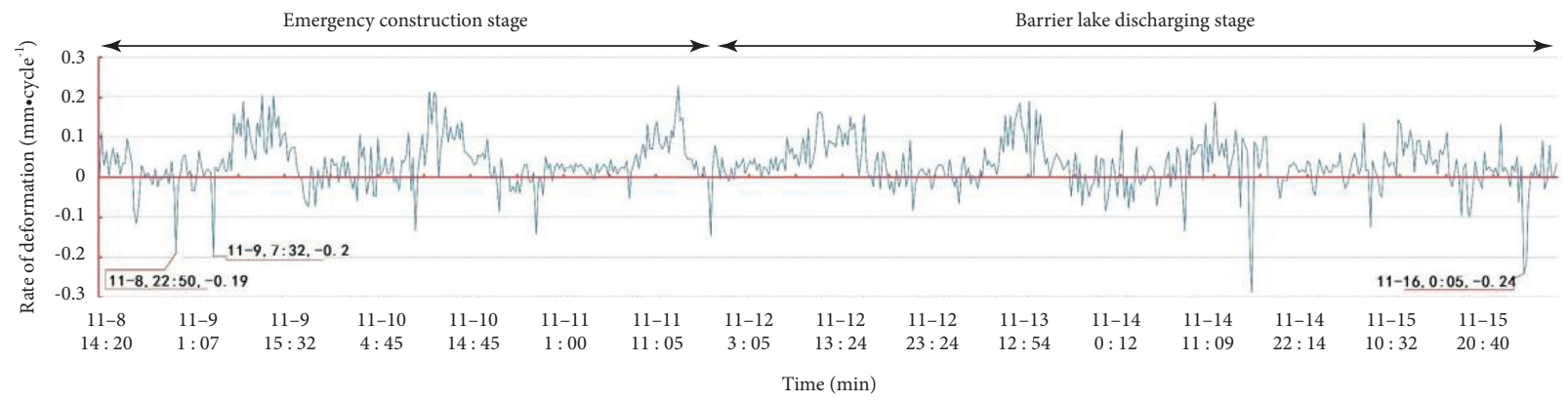

FIGURE 13: K3 J44 deformation rate-time curve.

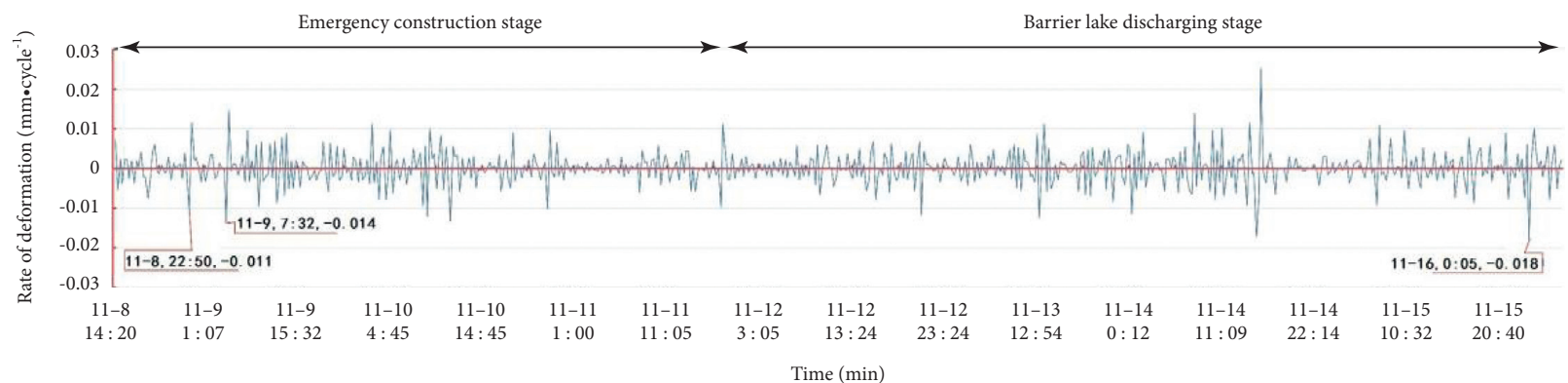

FIgURE 14: Deformation acceleration-time curve of J44 in the K3 region.

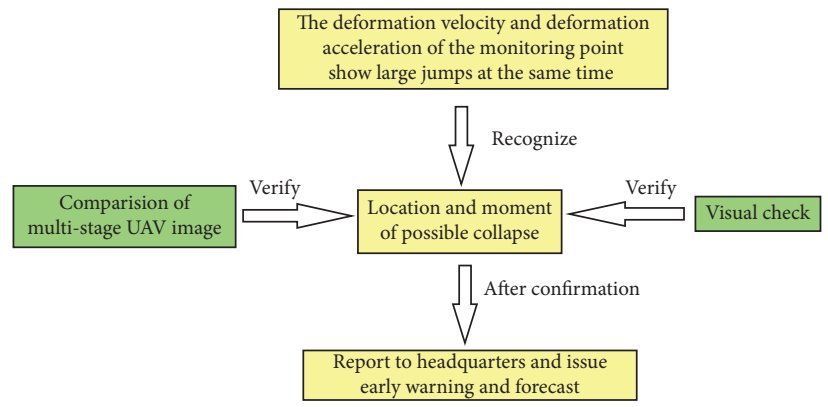

FIGURE 15: Flowchart of local critical slip failure identification and prediction. 
TABle 2: Possible locations and moments of imminent slip failure.

\begin{tabular}{lccc}
\hline $\begin{array}{l}\text { Position at which impending slip failure } \\
\text { may occur }\end{array}$ & $\begin{array}{c}\text { Moment of impending slip } \\
\text { failure }\end{array}$ & $\begin{array}{c}\text { Deformation rate (mm } \\
(15 \mathrm{~min}))\end{array}$ & $\begin{array}{c}\text { Deformation acceleration (mm } \\
(15 \mathrm{~min}))\end{array}$ \\
\hline J40 & November 10, 01:56 & 0.32 & 0.02 \\
J40 & November 14, 20:33 & 0.36 & 0.022 \\
J40 & November 15, 06:24 & 0.32 & 0.023 \\
J40 & November 15, 22:20 & 0.37 & 0.03 \\
J13 & November 9, 07:32 & 0.28 & 0.017 \\
J13 & November 13, 22:57 & 0.22 & 0.014 \\
J13 & November 14, 20:33 & 0.021 \\
J13 & November 15, 07:24 & 0.28 & 0.022 \\
J44 & November 8, 22:50 & 0.26 & 0.011 \\
J44 & November 9, 07:32 & 0.19 & 0.014 \\
J44 & November 16, 00:05 & 0.2 & 0.018 \\
\hline
\end{tabular}

\section{Conclusion}

On the basis of the field investigation and aerial photograph of the UAV, S-SAR was used in this study to carry out emergency landslide monitoring based on the 11.03 Baige landslide. The results can be summarized as follows:

1. After the 11.03 landslide, several tensile cracks emerged on the platform at the back edge and the left/right boundaries. The stability of the K1, K2, and $\mathrm{K} 3$ areas is relatively poor. Local rock falling and collapse of the shallow surface soil occurred during the monitoring period. Beidou displacement metre data indicate that the landslide mass experienced three separate iterations of accelerated deformation before the main sliding body began to slide.

(2) The S-SAR was applied to characterize the strong deformation area. The real-time pixel point cloud deformation map obtained via S-SAR was used to delimit four strong deformation areas in the deformed body. The overall deformation pattern of the $\mathrm{K} 1, \mathrm{~K} 2$, and $\mathrm{K} 3$ areas was monitored in real time.

(3) Distinct deformation stages across the deformation zone were also effectively assessed in this study to identify an early warning imminent sliding value. The K1, K2, and K3 zones are all in constant deformation stages. The early warning value of acceleration corresponding to an impending landslide, according to the S-SAR data of the 11.03 Baige landslide, is $0.03 \mathrm{~mm}(15 \mathrm{~min})^{-2}$.

(4) Local near-slip failure in deformation areas was also predicted effectively in this study. The target pixels and the corresponding time at which the deformation velocity and acceleration sharply jumped were used to determine the points of failure-11 potentially problematic points were identified in total across the study area. Combined with visual monitoring and multiphase UAV aerial image comparison results, this study suggests there is a danger that should be immediately reported to headquarters for the purpose of early warning.

The general advantages, disadvantages, and raw monitoring data of S-SAR and GNSS displacement monitoring systems were comprehensively assessed to find that the S-SAR system provides reliable and suitable information for both emergency and long-term monitoring of geological disasters such as landslides. The S-SAR monitoring time was short, so the conclusions based on the monitoring data are limited. In the future, we will continue to carry out multimeans monitoring on the rock mass of the 11.03 landslide to better understand the deformation patterns and characteristics of the landslide. The deformation and failure mechanism of the Baige landslide also merit further research.

\section{Data Availability}

All data, models, and codes generated or used during the study appear in the submitted article.

\section{Conflicts of Interest}

The authors declare that they have no conflicts of interest.

\section{Acknowledgments}

This project was funded by the China Geological Survey (Grant nos. DD20190640 and 20190505), the Sichuan Provincial Youth Science and Technology Innovation Team Special Projects of China (Grant no. 2017TD0018), the Team Project of Independent Research of SKLGP (Grant no. SKLGP2016Z001), and the National Natural Science Foundation of China (Grant nos. 41702374 and 41772324).

\section{References}

[1] J. H. Deng, Y. J. Gao, Z. Q. Yu, and H. Xie, "Analysis on the formation mechanism and process of baige landslides damming the upper reach of Jinsha river, China," Advanced Engineering Sciences, vol. 51, no. 1, pp. 9-16, 2019.

[2] M. Saito and M. Uezawa, "Failure of soil due to creep," in Proceedings of the 5th International Conference on Soil Mechanics and Foundation Engineering, pp. 315-318, Mexico, North America, 1961.

[3] M. Saito, "Forecasting time of slope failure by tertiary creep," in Proceedings of the 7th International Conference on Soil Mechanics and Foundation Engineering, pp. 677-683, Mexico, North America, 1969. 
[4] S. Hayashi, F. Komamura, and B.-W. Park, "On the forecast of time to failure of slope," Landslides, vol. 24, no. 4, pp. 11-18, 1988, https://doi.org/10.3313/jls1964.24.4_11.

[5] T Fukuzono, "A new method for predicting the failure time of a slope failure," in Proceedings of the 4th International Conference and Field Workshop on Landslides, pp. 145-150, 1985, https://doi.org/10.1016/0148-9062(87)91524-5.

[6] T. Fukuzono, "A method to predict the time of slope failure caused by rainfall using the inverse number of velocity of surface displacement," Landslides, vol. 22, no. 2, pp. 8-13, 1985, https://doi.org/10.3313/jls1964.22.2_8.

[7] T. Fukuzono, "Recent studies on time prediction of slope failure," Landslide News, vol. 4, pp. 9-12, 1990.

[8] T. Li, M. Chen, L. Wang, and Y. Zhou, "Time prediction of landslides using Verhulst inverse-function model," in Proceedings of the 7th International Symposium on Landslides, pp. 1289-1293, Trondheim, Norway, 1996.

[9] A. Mufundirwa, Y. Fujii, and J. Kodama, "A new practical method for prediction of geomechanical failure-time," International Journal of Rock Mechanics and Mining Sciences, vol. 47, no. 7, pp. 1079-1090, 2010, https://doi.org/10.1016/j. ijrmms.2010.07.001.

[10] B. Voight, "A method for prediction of volcanic eruptions," Nature, vol. 332, no. 6160, pp. 125-130, 1988, https://doi.org/ $10.1038 / 332125 \mathrm{a} 0$.

[11] B. Voight, "A relation to describe rate-dependent material failure," Science, vol. 243, no. 4888, pp. 200-203, 1989a, https://doi.org/10.1126/science.243.4888.200.

[12] B. Voight, "Materials science law applies to time forecasts of slope failure," Landslide News, vol. 3, pp. 8-11, 1989b.

[13] G. B. Crosta and F. Agliardi, "How to obtain alert velocity thresholds for large rockslides," Physics and Chemistry of the Earth, Parts $A / B / C$, vol. 27, no. 36, pp. 1557-1565, 2002, https://doi.org/10.1016/S1474-7065(02)00177-8.

[14] C. Kilburn, "Precursory deformation and fracture before brittle rock failure and potential application to volcanic unrest," Journal of Geophysical Research, vol. 117, no. B2, https:// doi.org/10.1029/2011jb008703, Article ID B02211, 2012.

[15] Y. Lavallée, P. G. Meredith, D. B. Dingwell et al., "Seismogenic lavas and explosive eruption forecasting," Nature, vol. 453, no. 7194, pp. 507-510, 2008, https://doi.org/10.1038/ nature 06980.

[16] S. Hao, C. Liu, C. Lu, and D. Elsworth, "A relation to predict the failure of materials and potential application to volcanic eruptions and landslides," Scientific Reports, vol. 6, no. 1, Article ID 27877, 2016, https://doi.org/10.1038/srep27877.

[17] K. Chousianitis, V. Del Gaudio, I. Kalogeras, and A. Ganas, "Predictive model of Arias intensity and Newmark displacement for regional scale evaluation of earthquake-induced landslide hazard in Greece," Soil Dynamics and Earthquake Engineering, vol. 65, pp. 11-29, 2014, https://doi. org/10.1016/j.soildyn.2014.05.009.

[18] Z. Liu, J. Shao, W. Xu, H. Chen, and C. Shi, "Comparison on landslide nonlinear displacement analysis and prediction with computational intelligence approaches," Landslides, vol. 11, no. 5, pp. 889-896, 2014, https://doi.org/10.1007/s10346-0130443-z.

[19] F. Miao, Y. Wu, Y. Xie, and Y. Li, "Prediction of landslide displacement with step-like behavior based on multialgorithm optimization and a support vector regression model," Landslides, vol. 15, no. 3, pp. 475-488, 2018, https://doi.org/ 10.1007/s10346-017-0883-y.

[20] J. Du, K. Yin, and S. Lacasse, "Displacement prediction in colluvial landslides, three gorges reservoir, China," Landslides, vol. 10, no. 2, pp. 203-218, 2013, https://doi.org/10.1007/ s10346-012-0326-8.

[21] M. Krkač, D. Špoljarić, S. Bernat, and S. M. Arbanas, "Method for prediction of landslide movements based on random forests," Landslides, vol. 14, no. 3, pp. 947-960, 2017, https:// doi.org/10.1007/s10346-016-0761-z.

[22] Z. Zou, J. Yan, H. Tang, S. Wang, C. Xiong, and X. Hu, “A shear constitutive model for describing the full process of the deformation and failure of slip zone soil," Engineering Geology, vol. 276, 2020 https://doi.org/10.1016/j.enggeo.2020. 105766, Article ID 105766.

[23] Q. Wang, M. C. He, S. C. Li et al., "Comparative study of model tests on automatically formed roadway and gob-side entry driving in deep coal mines," International Journal of Mining Science and Technology, vol. 31, no. 04, pp. 591-601, 2021, https://doi.org/10.1016/j.ijmst.2021.04.004.

[24] Q. Yin, J. Wu, C. Zhu, M. He, Q. Meng, and H. Jing, "Shear mechanical responses of sandstone exposed to high temperature under constant normal stiffness boundary conditions," Geomechanics and Geophysics for Geo-Energy and GeoResources, vol. 7, no. 2, p. 35, 2021, https://doi.org/10.1007/ s40948-021-00234-9.

[25] C. Zhu, M. C. He, X. H. Zhang, Z. G. Tao, Q. Yin, and L. F. Li, "Nonlinear mechanical model of constant resistance and large deformation bolt and influence parameters analysis of constant resistance behavior," Rock and Soil Mechanics, vol. 42, no. 7, pp. 1911-1924, 2021.

[26] L. Lombardi, M. Nocentini, W. Frodella et al., "The Calatabiano landslide (Southern Italy): preliminary GB-InSAR monitoring data and remote 3D mapping," Landslides, vol. 14, no. 2, pp. 685-696, 2017, https://doi.org/10.1007/s10346-0160767-6.

[27] A. Segalini, A. Valletta, and A. Carri, "Landslide time-offailure forecast and alert threshold assessment: a generalized criterion," Engineering Geology, vol. 245, pp. 72-80, 2018, https://doi.org/10.1016/j.enggeo.2018.08.003.

[28] D. Brox and W. Newcomen, "Utilizing strain criteria to predict highwall stability performance," in Proceedings of the 10th ISRM Congress, Sandton, South Africa, September 2003.

[29] Q. Xu, Y. Yuan, Y. P. Zeng, and R. Hack, "Some new prewarning criteria for creep slope failure," Science China Technological Sciences, vol. 54, no. 1, pp. 210-220, 2011.

[30] A. Cabrejo and N. Harries, "Effective slope monitoring for open cut coal mines," 2012, http://www.acarp.com.au/ abstracts.aspx?RepId=C17023.

[31] X. Li, K. Peng, J. Peng, and D. Hou, "Experimental investigation of cyclic wetting-drying effect on mechanical behavior of a medium-grained sandstone," Engineering Geology, vol. 293, Article ID 106335, 2021.

[32] X. S. Li, K. Peng, J. Peng, and H. Xu, "Effect of cyclic wettingdrying treatment on strength and failure behavior of two quartz-rich sandstones under direct shear," Rock Mechanics and Rock Engineering, 2021, https://doi.org/10.1007/s00603021-02583-z.

[33] E. Intrieri, F. Raspini, A. Fumagalli et al., "The Maoxian landslide as seen from space: detecting precursors of failure with Sentinel-1 data," Landslides, vol. 15, no. 1, pp. 123-133, 2018, https://doi.org/10.1007/s10346-017-0915-7.

[34] T. Carlà, P. Farina, E. Intrieri, H. Ketizmen, and N. Casagli, "Integration of ground-based radar and satellite InSAR data for the analysis of an unexpected slope failure in an open-pit mine," Engineering Geology, vol. 235, pp. 39-52, 2018, https:// doi.org/10.1016/j.enggeo.2018.01.021. 
[35] N. D. Rose and O. Hungr, "Forecasting potential rock slope failure in open pit mines using the inverse-velocity method," International Journal of Rock Mechanics and Mining Sciences, vol. 44 , no. 2 , pp. 308-320, 2007, https://doi.org/10.1016/j. ijrmms.2006.07.014.

[36] T. Carlà, P. Farina, E. Intrieri, K. Botsialas, and N. Casagli, "On the monitoring and early-warning of brittle slope failures in hard rock masses: examples from an open-pit mine," Engineering Geology, vol. 228, pp. 71-81, 2017, https://doi.org/ 10.1016/j.enggeo.2017.08.007.

[37] G. J. Dick, E. Eberhardt, A. G. Cabrejo-Liévano, D. Stead, and N. D. Rose, "Development of an early-warning time-of-failure analysis methodology for open-pit mine slopes utilizing ground-based slope stability radar monitoring data," Canadian Geotechnical Journal, vol. 52, no. 4, pp. 515-529, 2015, https://doi.org/10.1139/cgj-2014-0028.

[38] Q. Xu, G. Zheng, W. L. Li et al., "Study on successive landslide damming events of Jinsha River in Baige village on Octorber 11 and November 3,2018," Journal of Engineering Geology, pp. 1534-1551, 2018.

[39] X. Zheng, X. Yang, H. Ma et al., "Integrated ground-based SAR interferometry, terrestrial laser scanner, and corner reflector deformation experiments," Sensors, vol. 18, no. 12, Article ID 4401, 2018, https://doi.org/10.3390/s18124401.

[40] X. Li, Q. Xu, and R. Huang, "Research on prediction criterion for temporary prediction of landslide," Chinese Journal of Geological Hazard and Control, pp. 5-11, 2003.

[41] Q. Wang, Y. Wang, M. C. He et al., "Experimental research and application of automatically formed roadway without advance tunneling," Tunnelling and Underground Space Technology, vol. 114, Article ID 103999, 2021, https://doi.org/ 10.1016/j.tust.2021.103999.

[42] Q. Xu, Y. P. Zeng, J. P. Qian, and C.-J. Wang, "Study on a improved tangential angle and the corresponding landslide pre-warning criteria," Geological Bulletin of China, pp. 501505, 2009. 